\title{
Analysis of College students' Sex Differentiation in English Sound
}

\author{
Dongmei Sheng \\ Foreign Language Department \\ Jilin Business and Technology College \\ Changchun, China \\ 455635403@qq.com
}

\begin{abstract}
The aim of this study is to search for the best teaching method to improve the college students' pronunciation. This paper presents an analysis of sex differentiation in English sound. The sound is analyzed from five aspects, which are absolute pitch, tone and intonation, phoneme, pronunciation of words and stress. This paper also presents the sex differentiation from different age, emotion, social position and social work. The result shows that the sex differentiation attributed from different age and emotion, social position and social work. The result suggests that the better teaching method in pronunciation is of great significance in improving college students' oral English ability.
\end{abstract}

Keywords-dialect; absolute pitch; tone and intonation; phoneme

\section{INTRODUCTION}

As long as a country or a group exists, there must be a certain language used by members. Besides there is a variety that is not used in print and is different from the standard language in phonetics, vocabulary, grammar, etc, we call it dialect. Dialects, which identify are called social dialect where a person is in terms of a social scale. Dialect is connected very closely with sex of the speaker. In the society there is a variety that is not used in print and is different from the standard language in phonetics, vocabulary, grammar, etc, we call it dialect. Dialects, which identify where a person is in terms of a social scale, are called social dialect. Male and female are regarded as two main factors in society. They have many differences when they speak[1]. Here we mainly talk about sex differentiation in sound in four aspects.

\section{ANALYSIS OF ENGLISH SOUND}

Voice learning concept can be understood as a view that is formed by the learners in the learning process experience the influence of the outside world [2]. The experts had the concept of gender differences in learning English pronunciation of college students. They have done the research about content related to speech learning objectives, evaluation criteria, the importance of the voice and speech learning evaluation. Actually, English pronunciation learning hypothesis in speech learning process also plays an important role in self-concept pronunciation. Therefore, the author thinks that pronunciation learning involving three variables: phonetic learning motivation; speech learning objectives; pronunciation self- concept. If learners Have a higher speech learning motivation, establish the clear goal and form the active voice in self concept, they should promote its pronunciation effect as a whole.

Another concern is the rules of the segmental feature compensation strategies for boys and girls. Compensation strategies use lowest frequency in the process of using the frequency of this strategy, which is slightly higher than that of girls. For speech compensation strategy, the definition refers to learners in the learning process of voice. Through imitation the use is closest to the target language pronunciation instead of the standard pronunciation. In target language contact does not have the rich environment. The compensation of speech learning strategies often uses more strategies according to the Chinese English learning environment. The characteristics of their own voice can be as a mother tongue transfer strategy. Generally it is believed that language transfer is a kind of negative transfer and according to the analysis the transfer is to internalize the target language rules process.

So the speech learning in the process of compensation strategy role is positive. It often occurs in learning English pronunciation. Compensation strategies are inevitable for many primary and middle school students, who rely on phonetic symbols. Chinese characters help them remember the English phonetic, simplify the pronunciation of English words and achieve good results, which is an indisputable fact.

However, with the deepening of learning and the increase of target language exposure, learners should try to avoid the use of compensation strategy, which is the starting point for the English Majors in the course of the creation of pronunciation. If the compensation strategy is dependent on the accuracy and the level of the learners' pronunciation, the accuracy and the level of the compensation will be blocked. The students who participated in the survey were intermediate English learners, so the compensation strategy should be avoided, which may be one of the reasons why male students have lower scores than female students.

A lot of male students in elementary school and junior high school learn the experience. College students will read and memorize the sentence, then turn their attention on expanding their vocabulary and deal with all kinds of examinations, rather than practicing and correcting speech, which results in low accuracy of their pronunciation and word pronunciation. 


\section{A. Absolute pitch}

In our mind there is a stereotyped impression: males are in low voice and female in high voice. Yes, that's true. The vibration of vocal organ decides pitch. In a fixed time, if sound A vibrates 500 times per second and sound B vibrates 300 times per second, we conclude that a is higher than B. For female, their vocal cords are thin and short. Their sound frequency is $150-300 \mathrm{HZ}$; while male, their vocal cords are long and thick and their sound frequency is $60-200 \mathrm{HZ}$. So we say woman will have higher voice than man. (Normally we refer to absolute pitch).

\section{B Tone and Intonation}

Man and woman are different in intonation. Commonly, women like rising tone and often change the tone; men are used falling tone and seldom change the tone. In Japan, when Japanese woman receive the telephone, they will use high tone to say “もしもし” (“hello”). When the caller dials wrong, she will say “ちかでます” (“You dial wrong”) in low voice. It is said that Japanese woman will use low tone when they talk to their children's friends, clerks in coffee house, etc. They feel that these people are inferior to themselves.

\section{Pronunciation}

In American English, there is some difference between male and female speech in regional dialectal variety. Here we deal with some of them. A something about (ng) (ng) is the pronunciation of the suffix "ing" in present participles, such as "walking, reading" etc. In most varieties of English, the final consonant of this suffix is variable alternating between [n] and $\eta \eta]$, Norwich, words like "walking" can be pronounced either[wo:kiך]or 【wo:kin】. Usually in some formal occasions, people prefer 【wo:kin】.rather than 【wo:kin】. Thus we mark like this: $(\mathrm{ng}) 1=\lfloor\mathrm{\eta} 】(\mathrm{ng}) 2=【 \mathrm{n} 】$. Using some methods, consistent use of (ng)2 will produce a score of 100 and consistent use of (ng) 1 will get 0 , so we get the following: We see that in each social group, male speakers have higher score (more low status "n" variants) than female speakers. Women tend on average to use higher status variants than men do. Men usually pronounce "in” after the voiced consonants, nasal consonants vowels and some fricatives such as: flubbing, swimming, going, chewing, etc.

\section{$D$ Something about phoneme / $/$}

Britain linguist Trudgill said in his book Socialinguistics: an Introduction that in American Automobile Industry Center Detroit, female will pronounce $/ \mathrm{r} /$ either in a single word or in a sentence, such as "car". Trudgill once had the following to show females like $/ \mathrm{r} /$ Not only adults have difference in pronouncing $/ \mathrm{r} /$, this difference also occur in the speech of children [3]. For example, in the pronunciation of postvocalic $/ \mathrm{r}$ /in Edinburgh English, it was shown that there was a pattern of sex differentiation even in the speech of six-year-old children. $/ \mathrm{r} /$ has three variants in Edinburgh [I] (a tap) [ $\lambda]$ (a frictionless continuant) and zero. If we examine the first two of these, we can see that children from all three age groups studied are consistent. Boys prefer $[C]$ and girls prefer $[\lambda]$.
The variants $[\lambda]$ are associated especially with Middle class speech in Scotland and it is of course significant that girls favor this form. In French, there is such difference. Variables studied in a survey of French spoken in Montreal were [1]. This deals with the presence or absence of the consonant in the pronunciation of the pronouns "il" (he, it), "elle" (she, it), "ils" (they), "la" (her, it), "les" (them) and definite articles "la" (feminine singular) and "les" (plural). This variable, obviously has two variants (l) $1=$ [l] and (l) $2=$ =zero. [IL] is socially more prestigious and is regarded as more "correct" than zero variant, as"il” [i]. Some analysis shows that men are clearly more likely than women to use the low prestige variant.

There was a Norwich study on the effects of correct prestige on men and women [4]. As part of the study, speakers were asked to say which of the two pronunciations of particular words they used, for example [bet] or [be] (better).It was then possible to check with tape recording how accurate their pronunciation is. Not surprising, many people claimed to say [betə ]when they actually said $\mathrm{r}[\mathrm{be \zeta}$ ○]. More surprisingly, there were many informants who did the reverse and claimed to say [beלə] when they actually said [betə] . There is no suggestion that people were being deceitful here. In Norwich, Trudgill also had such similar experiment. He studied the pronunciation of word "ear". Its standard pronunciation is [iə]. While people living in Norwich or around Norwich sometimes pronounced [عə]. The "air" was confusing with "ear" because the "ear" was pronounced as [عə]. Trudgill wanted to know the using of frequency of [iə] and [عə]. The result was that $20 \%$ of men were right to utilize the standard pronunciation; less than $20 \%$ of women were right. More than $68 \%$ women claimed that their pronunciation was correct [iə], and in fact many of them did not.

\section{E Stress}

In the town of Trondheim of Norway, some loan-words such as "avis"(newspaper) should be pronounced [av'i;s] as its standard pronunciation. They are stressed on the final syllable. But in lower status Trondheim speech, they are stressed on the first syllable, a stereotyped feature of lower class speech in many parts of Norway. There also is an investigation: Stress assignment in Trondheim NorwegianFrom this, we can deduce that men use more nonstandard stress forms than female when they are in the same group. In China, there is such difference, too. In informal occasions, young males in Beijing like speaking in soft voice. They will mistake some consonants for retro flexional vowels. The pronunciation is confusing. Young females seldom say like this, or she will be thought to be rough.

\section{F . Phoneme}

A sound, which is capable of distinguishing one word or one shape of a word from another in a given language, is a phoneme [5]. In American English, there is some difference between male and female speech in regional dialectal variety. When females pronounce low vowels, they will have low position than males do; when females pronounce high vowels, they will have high position than male do. For front vowels or back vowels, females will pronounce more forward or backward. For example: Britain linguist Trudgill said in his book Socialinguistics: An Introduction that in American 
Automobile Industry Center Detroit, female will pronounce 【r】 more often than male.

\section{FOUR ASPECTS OF SEX DifFERENTIATION IN SOUND}

The absolute pitch is determined by physiological reason and we will discuss no more. The females are emotional. When they want to show their feeling, they can prolong modal particle, interrogative particle, etc. In China, it is easy to understand. The sentence in different circumstances and use different intonation it can show different meaning and feeling, either doubt, politeness, irony, etc. When female reads it, she needs prolong to show her different emotion. So females have variable intonation.

We have known that women are more likely than men in using normal patterns and standard pronunciation. Men and women are different in social position and social work. In people's mind, men are dominating in the world.. Since women have fewer opportunities, they are likely to signal their social status by how they appear and behave (including linguistically) than by what they do. Also since women have fewer chances to participate in social networks, they are less subjected to the same group pressure than man. When they are talking to others, they feel themselves informal, so they would like to train their formal style in speaking.

It is believed that speech and reading problems very often affected the males while females usually learn to talk earlier and learn foreign languages faster and better. Sometimes, sex differentiation in sound is influenced by educational level.Nader Jahagiri once visited 40 people who speak Persian. Focusing on vowel assimilation, he got this: there are five columns and every line has eight people, these people are in the same social class but different educational level. We can see that men have more chances to have vowel assimilation. Only when males have higher education than females can males keep up with females or better than females in vowel assimilation. Different educational level leads to sex differentiation in sound.

Traditional ideas require that females should be kind, gentle, polite and emotional. Young girls are pursuing beauty. Society requires them to speak softly, open mouth not too big, so many young girls try to do better and little by little, they will pronounce some words forward. There is a typical example in China [6]. In the 1920s, Lijinxi mentioned a phenomenon which had happened in Beijing Women, required by traditional rule, moved “j, q, and x" forward and became " $\mathrm{z}$, c, s" in some informal occasions, .Not in formal occasions. Sixty-five males were studied and they didn't pronounce like this. Among 137 females, 42 people had this habit. The following example will help you understand this one better. A certain life style and other people's imposing can affect the sex differentiation in sound. If people are inconvenient to contact with the out world for some reasons and they have less chances to change their speech. Ballymacarrett, a small village, is the working class enclave of Protestant east Belfast in Northern Ireland. It is a self - contained area and it has its own industrial district where most of men work within a two-minute-walks from their house. When young men leave school, they generally enter the plants in the district and frequent the same pubs and clubs as their fathers do. This kind of life style has been emphasized in recent years by the violence between Catholics and Protestant in the city, so that since 1969, the men have seldom crossed the bridge over the river Lagan that separates east Belfast from the rest of the city. Under this circumstance, people have to contact people in this district. There is a research shows that the men are remaining their original pronunciation and use less standard variant than women. Who have some variety in language, and sex differentiation forms.

Masculinity is an important symbol for men. They are taught to be tough, firm and hard-working. It is not surprising for a man to say rough words in public; it will be surprising for a woman to do so. But if a man says words gently, we will not accept. In a video The Notting Hill, a man who is frightened to climb a wall says "my mama", we all feel uncomfortable, although it will show some special effect. For men, since they need masculinity and dignity, and local variants, nonstandard pronunciation can show their individuality, then they like these words. Since women are encouraged to be discreet, quiet and polite in this behavior, pressures on women to use "correct" linguistic forms are greater than those on men. Men, on the other hand, appear at some level of awareness to be more favorably disposed than women to low status speech forms. This may well be because of the connotation of roughness, toughness and masculinity.

Labor has ever said: when the social class is classified by language, females are longing for higher social position and prestige. If they are fixed in a certain position, they have no motive in changing language. Only when their positions change, they want to change the language to keep up with the position. They need to be equal with men, so linguistically some innovation is taking place. Young women are easily influenced than old women in linguistic change. There is a good illustration in Ballymacarrett in Belfast. Research on two variables: variable (Th) measures the percentage of deletion of [] medially in words like "mother". Variable [^] measures the percentage of no rounded [ $\wedge$ ] in a set of lexical items that includes "pull, push, took" etc. Look at the figure"

Let's have a comparison in groups: males in different age, females in different age. We see that young men have higher scores than older men by about $6 \%$ for (th) and $17 \%$ for []. While at the same time, younger women and older women are the same in (th) and [^] are declining. This shows that women are making linguistic innovation in the direction of this small city. We have mentioned above that in this city, men seldom go outside especially when the violence between Catholic and Protestant has taken place. Men are the supporter of the whole district, so they have to keep the benefit of the whole group. While women are not so limited by this kind of restricted life style; many older women work as office cleaner outside the district and the younger women often have clerical jobs across the river. The younger women can have social and occupational ties beyond the boundaries of this city. Consequently, the women are the innovators of linguistic change in the district.

A survey shows that there is a certain relationship between the attitude of foreign language learning and gender. Compared with boys, girls are more positive in foreign language learning 
Girls have a strong interest in learning English, learning behavior. But most of the boys do not have strong motivation to learn English, without confidence [7]. The boys think English is difficult to learn, have no talent in learning English and not have interested in English. It is specific to have English pronunciation attitude and also have differences. Girls have more tendencies to keep the standard pronunciation, whose pronunciation is higher than that of boys .Exploring and attitude towards foreign language learning attitude is caused by the effect of gender differences, which is one of the important factors in foreign language learning. A large numbers of domestic and foreign research results show those women in foreign language learning more active than boys. Their advantages are more or less reflected in the listening, speaking, reading and writing. In terms of speech, girls also have a slight advantage in the acquisition of English, especially in her stress, tone, the rising tone and falling tone. Their skills are closer to native speakers than boys.

\section{CONCLUSIONS}

The reasons why such differences exist are complicated. Females are emotional. When they want to show their feeling, they can prolong modal particle, interrogative particle, etc. In China, it is easy to understand. In different circumstances and use different intonation it can show different meaning and feeling, either doubt, politeness, irony, etc. When female reads it, she needs show her different emotion. So females have variable intonation. We have known that women are more likely than men in using normal patterns and standard pronunciation.

Men and women are different in social position and social work. In people's mind, men are dominating in the world. Since women have fewer opportunities, they are likely to signal their social status by how they appear and behave (including linguistically) than by what they do. When they are talking to others, they feel themselves informal, so they would like to train their formal style in speaking. Women's traditional great role to raise children leads them to be more sensitive to norms of “accepted” behavior. Language surrounding influences sex differentiation. Children will first meet some females when they were born, the mother, the nurse, etc, no matter boys or girls. So these children will first learn some feminine language. Mothers will teach their daughters how to say and how to do. Girls are subconsciously pay attention to their language and they are easy to remember and imitate. Different sexes learn language they like from different people.

It is true that sex differentiation in sound exists and it has existed for a long time. Different people have different intonation because of different physiological reason. Dialect is a social and historical product, so it is difficult to define its future whether it will exist or not. Until now, it has a long way to go to explain and solve the sex differentiation in sound in social dialect.

\section{REFERENCES}

[1] Wardlhaugh, R. An Introduction to Sociolinguistics Oxford: Basil Blackwell Lirnited, 1986.

[2] Ehrman M. The role of personality type in adult language learning an ongoing investigation Parry and Stansfield (eds) Lan-guage Aptitude ReconsidereEnglewood Cliffs. N. J. PrenticeHall,1990.

[3] Bacon S M. The relationship between gender, comprehension,processing strategies and cognitive and affective response in foreign listening. Modern Language Journal, 1992,( 2) : 160-178.

[4] Goh C. M, Foong K P. Chinese ESL students' learning strategies: Alook at frequency, proficiency, and gender Hong Kong Journal of Applied Linguitics,1997,2( 1) : 39-53.

[5] Ford R L. Language Learning Strategies: What Every Teacher Should Know Bostonm :Heinle1990.

[6] O’Malley J M, Chamot G. Learning Strategy Applications with Students of English as a Second Language TESOL Quarterly,1985,(19) : 557584.

[7] Stern H H. Fundamental Concepts of Language Teaching. Oxford Oxford University Press,1983. 